NASA Technical Memorandum 107136

\title{
Finite Width Coplanar Waveguide Patch Antenna With Vertical Fed Through Interconnect
}

Rainee N. Simons

NYMA Inc.

Brook Park, Ohio

Richard Q. Lee and Kurt A. Shalkhauser

Lewis Research Center

Cleveland, Ohio

Jonathan Owens, James Demarco, Joan Leen, and Dana Sturzebecher PSD, Army Research Laboratory, AMSRL-PS-E

Fort Monmouth, New Jersey

Prepared for the 1996 IEEE AP-S International Symposium and URSI Radio Science Meeting cosponsored by IEEE, AP-S, and U.R.S.I.

Baltimore, Maryland, July 16-21, 1996

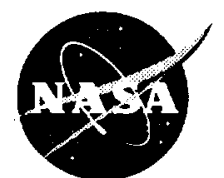

National Aeronautics and Space Administration 
Trade names or manufacturers' names are used in this report for identification only. This usage does not constitute an official endorsement, either expressed or implied, by the National Aeronautics and Space Administration. 


\title{
FINITE WIDTH COPLANAR WAVEGUIDE PATCH ANTENNA WITH VERTICAL FED THROUGH INTERCONNECT
}

\author{
Rainee N. Simons", Richard Q. Lee ${ }^{\circ}$, Kurt A. Shalkhauser \\ 'NASA Lewis Research Center Nyma Group, "NASA Lewis Research Center, \\ 21000 Brookpark Road, Cleveland, Ohio 44135 \\ Jonathan Owens, James Demarco, Joan Leen \\ and Dana Sturzebecher \\ PSD, Army Research Laboratory (ARL), AMSRL-PS-E, Fort Monmouth, \\ New Jersey 07703
}

\begin{abstract}
The paper presents the design, fabrication and characterization of a finite width coplanar waveguide (FCPW) patch antenna and a FCPW-to-FCPW vertical interconnect. The experimental results demonstrate the antenna and interconnect performance. A scheme to integrate an eight element FCPW patch array with MMIC phase shifters and amplifiers using vertical interconnects is described. The antenna module has potential applications in an advanced satellite to ground transmit phased array at K-Band.
\end{abstract}

\section{INTRODUCTION:}

A Finite Width Coplanar Waveguide (FCPW) on a dielectric substrate consists of a center strip conductor separated from finite ground planes by narrow slots on either sides [1] as shown in Fig. 1. The substrate thickness, the strip width, the slot width and the ground plane width are denoted as $D, S, W$ and $G$ respectively. The FCPW has all the advantages of conventional CPW [2] and in addition the finite ground planes suppress, the propagation of spurious substrate modes. The spurious substrate modes at high frequencies can degrade the electrical performance of an array antenna. In the past several authors [3], [4] have investigated conventional CPW patch antennas at $4.3 \mathrm{GHz}$ and $8.5 \mathrm{GHz}$ respectively fabricated on a low dielectric constant substrate, $\varepsilon_{\mathrm{r}}=2.2$. This paper discusses first, the design, fabrication and experimental characterization of a FCPW patch antenna with an integrated feed at K-Band. The width of the CPW ground planes are arbitrarily taken as twice the center strip conductor width which results in a very compact feed design. The entire circuit is fabricated on a low temperature co-firing ceramic tape (Ferro Corp.), $\varepsilon_{r}=5.9$. The higher dielectric constant of the substrate material helps to reduce the size of the patch which results in a compact array. The conductor pattern is deposited using gold paste and low cost screen printing technique. Second, the measured performance of a FCPW-to-FCPW vertical fed through interconnect is presented. Lastly, the vertical integration of an eight element FCPW patch array with a system level integrated circuit (SLIC) module consisting of MMIC phase shifters and amplifiers is described. The resulting tile subarray has potential applications in an advanced satellite to ground transmit phased array. 


\section{INTEGRATED FCPW PATCH ANTENNA:}

a.) Construction:

A schematic illustrating the integrated FCPW patch antenna is shown in Fig. 1. The antenna is constructed by widening the center strip conductor of the FCPW to form a rectangular patch. The lowest order of resonance for the patch occurs when the mean slot length summation a-thru- $i$ is one guide wavelength $\lambda_{\text {g(slot) }}$. At resonance the electric field lines are as shown in Fig. 1 . The antenna radiates with a polarization parallel to the side $\mathrm{c}-\mathrm{d}$ or $\mathrm{f}-\mathrm{g}$.

\section{b.) Measured Characteristics:}

The input impedance of the antenna is determined using THRU-REFLECTLINE on-wafer calibration standards, a pair of G-S-G microwave probes, HP8510C ANA and NIST De-embedding software [5]. The TRL standards are also fabricated on the same substrate as the antenna using the screen printing process. The experimentally de-embedded input impedance at the reference plane $P-Q$ is shown in Fig. 2. The antenna resonates at about $19.95 \mathrm{GHz}$. The measured E-and H-Plane radiation patterns, gain and the cross-polarization level will be discussed at the conference.

\section{FCPW-to-FCPW VERTICAL INTERCONNECT:}

A schematic illustrating two back-to-back FCPW-to-FCPW vertical interconnect with a short length of FCPW in between is shown in Fig. 3. The via has a diameter of about 0.01 inch. The rest of the dimensions are same as in Fig. 1. The measured return loss and insertion loss are shown in Fig. 4. These measurements show that, the insertion loss and return loss per interconnect is about $0.3 \mathrm{~dB}$ and $-30 \mathrm{~dB}$ respectively.

\section{INTEGRATION OF ANTENNA OVERLAY WITH SLIC MODULE:}

The SLIC module is being developed by Lockheed Martin under a contract from NASA Lewis Research Center. The module consists of four dual channel MMICs with supporting circuitry. Each of the dual channels consists of a 3-bit phase shifter, an analog attenuator and amplitude calibration and control elements. In addition, the module also has a photonic link to bring the $20 \mathrm{GHz}$ RF signals and digital control signals. A second link returns module status to the controller. Fig. 5 schematically illustrates the integration of the antenna overlay with the SLIC module. The results of the overlay characterization will be presented at the conference.

\section{REFERENCES}

[1] R.N. Simons and R.Q. Lee, "Coplanar Waveguide Aperture Coupled Patch Antennas with Ground Plane/Substrate of Finite Extent," Electron. Lett., Vol. 28, No. 1, pp. 75-76, Jan. 1992.

[2] K.C. Gupta, R. Garg and I.J. Bahl, Microstrip Lines and Slotlines, Dedham, MA: Artech House, 1979, Chap. 7 on Coplanar Lines.

[3] J.W. Greiser, "Coplanar Stripline Antenna," Microwave Journal, Vol. 19, No. 10 , pp. 47-49, Oct. 1976.

[4] H.-C. Liu, T.-S. Horng and N.G. Alexopoulos, "Radiation of Printed Antennas with a Coplanar Waveguide Feed," IEEE Trans. Antennas and Prop., Vol. 43, No. 10, pp. 1143-1148, Oct. 1995.

[5] NIST De-embedding Software, Program DEEMBED, Revision 4.04, 1994. 


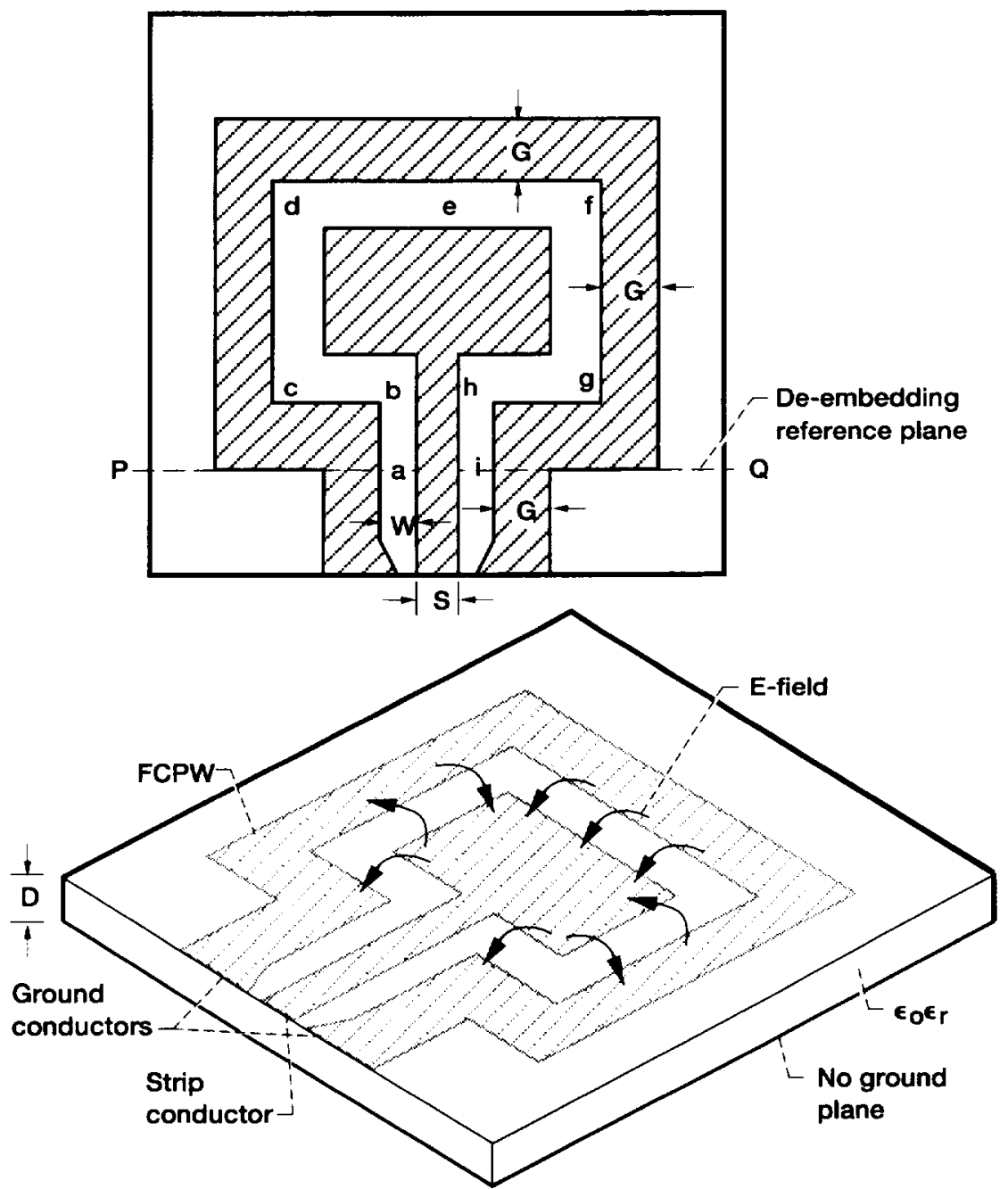

Figure 1. Schematic of FCPW patch antenna. $\epsilon_{r}=5.9, D=0.01125$ in., $S=0.012$ in., $W=0.004$ in. and $G=0.024$ in.

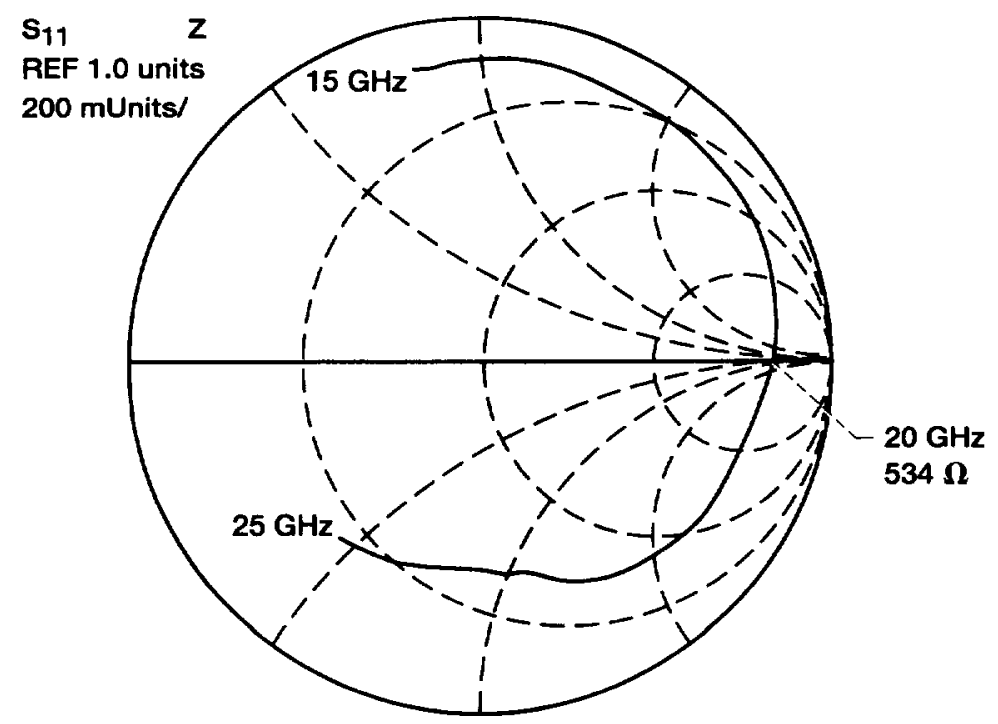

Figure 2.-Measured input impedance of the antenna. 


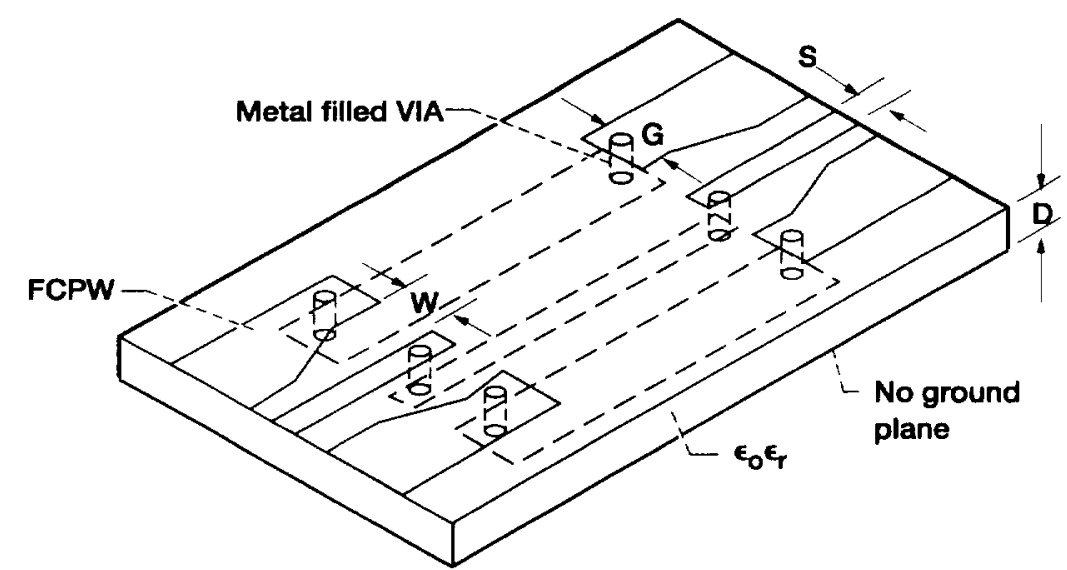

Figure 3.-Schematic of two back-to-back FCPW-to-FCPW vertical interconnect. $D=0.01125$ inch, $\epsilon_{r}=5.9$.
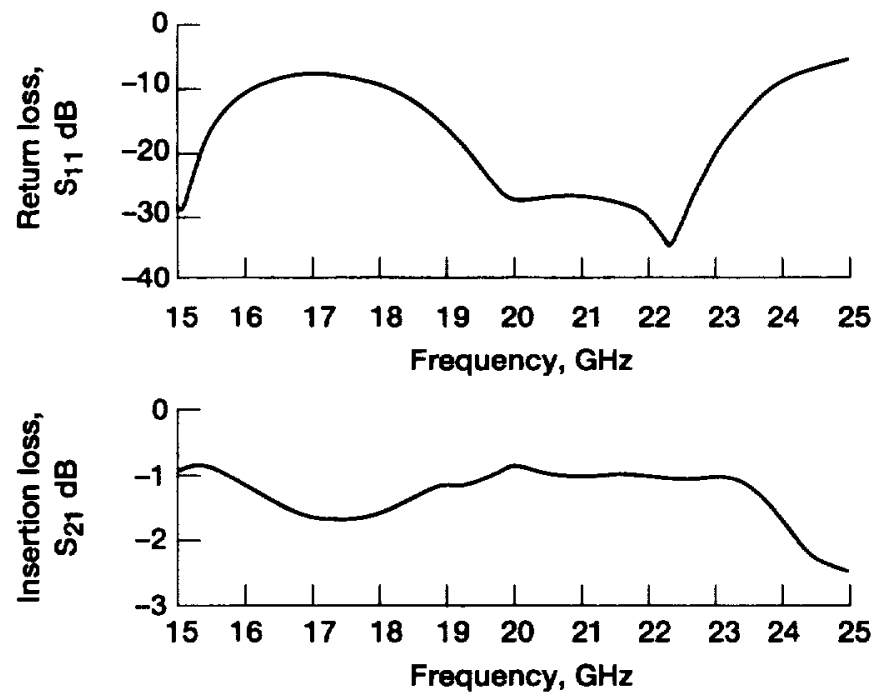

Figure 4.-Measured retum loss and insertion loss of the interconnect.

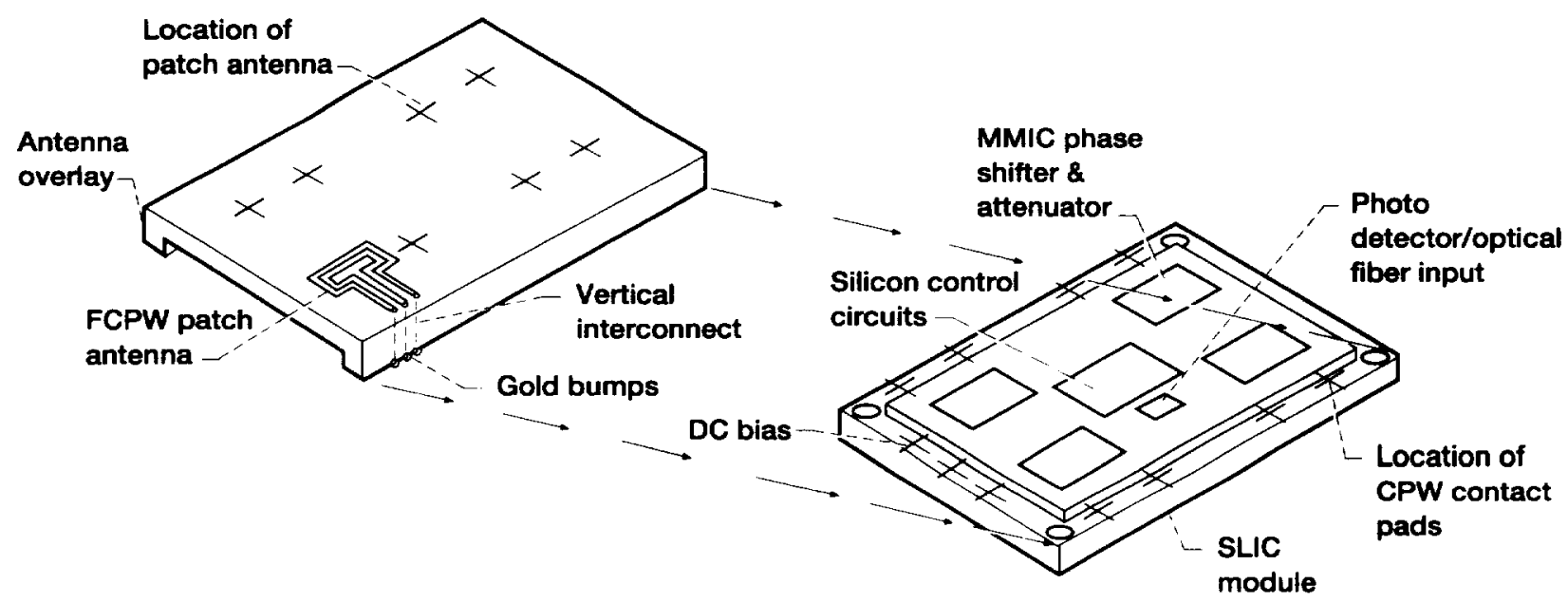

Figure 5.-Schematic of the SLIC module with the antenna overlay. 
Public reporting burden for this collection of information is estimated to average 1 hour per response, including the time for reviewing instructions, eearching existing data sources gathering and maintaining the data needed, and completing and reviewing the collection of information. Send comments regarding this burden estimate or any other aspect of this collection of information, including suggestions for reducing this burden, to Washington Headquarters Services. Directorate for Information Operations and Reports, 1215 Jefferson Davis Highway, Suite 1204, Artington, VA 22202-4302, and to the Office of Management and Budget, Papenwork Peduction Project (0704-018B), Washington, DC 20503.

\begin{tabular}{|l|c|l|}
\hline 1. AGENCY USE ONLY (Leave blank) & $\begin{array}{c}\text { 2. REPORT DATE } \\
\text { June } 1996\end{array}$ & $\begin{array}{r}\text { 3. REPORT TYPE AND DATES COVERED } \\
\text { Technical Memorandum }\end{array}$ \\
\hline
\end{tabular}

\section{TITLE AND SUBTITLE}

5. FUNDING NUMBERS

Finite Width Coplanar Waveguide Patch Antenna With Vertical Fed

Through Interconnect

6. AUTHOR(S)

Rainee N. Simons, Richard Q. Lee, Kurt A. Shalkhauser, Jonathan Owens, James

Demarco, Joan Leen, and Dana Sturzebecher

7. PERFORMING ORGANIZATION NAME(S) AND ADDRESS(ES)

8. PERforming organization REPORT NUMBEA

National Aeronautics and Space Administration

Lewis Research Center

Cleveland, Ohio 44135-3191

E-10066-1

9. SPONSORING/MONITORING AGENCY NAME(S) AND ADDRESS(ES)

National Aeronautics and Space Administration

Washington, D.C. 20546-0001

10. SPONSORINGMONITORING AGENCY REPORT NUMBER

NASA TM-107136

\section{SUPPLEMENTARY NOTES}

Prepared for the 1996 IEEE AP-S International Symposium and URSI Radio Science Meeting cosponsored by IEEE, APS, and U.R.S.I., Baltimore, Maryland, July 16-21, 1996. Rainee N. Simons, NYMA Inc., 2001 Aerospace Parkway, Brook Park, Ohio 44142 (work funded by NASA Contract NAS3-27186); Richard Q. Lee and Kurt A. Shalkhauser, NASA Lewis Research Center; Jonathan Owens, James Demarco, Joan Leen, and Dana Sturzebecher, PSD, Army Research Laboratory, AMSRL-PS-E, Fort Monmouth, New Jersey 07703. Responsible person, Richard Q. Lee, organization code $5600,(216) 433-3489$.

12a. DISTRIBUTIONJAVAILABILITY STATEMENT

12b. DISTRIBUTION CODE

Unclassified - Unlimited

Subject Category 33

This publication is available from the NASA Center for AeroSpace Information, (301) 621-0390.

13. ABSTRACT (Maximum 200 words)

The paper presents the design, fabrication and characterization of a finite width coplanar waveguide (FCPW) patch antenna and a FCPW-to-FCPW vertical interconnect. The experimental results demonstrate the antenna and interconnect performance. A scheme to integrate an eight element FCPW patch array with MMIC phase shifters and amplifiers using vertical interconnects is described. The antenna module has potential applications in an advanced satellite to ground transmit phased array at K-Band.

\section{SUBJECT TERMS}

Microwave transmission; Microwave antennas; Electronic packaging

17. SECURTY CLASSIFICATION OF REPOFT

Unclassified
18. SECURTY CLASSIFICATION OF THIS PAGE

Unclassified
19. SECURITY CLASSIFICATION OF ABSTRACT

Unclassified
15. NUMBER OF PAGES 07

16. PRICE CODE

$\mathrm{A02}$

20. LIMITATION OF ABSTRACT 


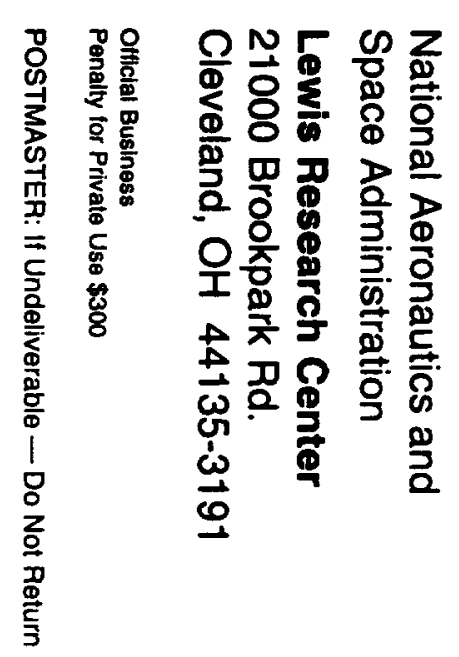

